\title{
Normal Contractile State of Hypertrophied Myocardium after Pulmonary Artery Constriction in the Cat
}

\author{
John F. Williams, JR., and Ralph D. Potter \\ From the Cardiology Division, Department of Medicine, University of Texas \\ Medical Branch, Galveston, Texas 77550
}

A B S TRACT The contractile function of right ventricular papillary muscles from normal cats and cats in which the pulmonary artery had been constricted for 6 or 24 wk was examined. Acute pulmonary artery constriction reduced cross-sectional area by an average of $70 \%$, resulting in a $30 \%$ mortality from congestive heart failure, all such deaths occurring within the first 3 wk after banding. The increase in right ventricular mass in animals surviving for 6 or 24 wk was similar, averaging $70 \%$. No banded animals had evidence of congestive heart failure at the time of sacrifice, and cardiac output and right atrial pressures were similar to those in control animals.

6 wk after banding, the active length-tension curve, maximal rate of rise of isometric force, force-velocity relations, and isometric force with paired stimulation and norepinephrine were all significantly depressed when compared to their respective values in control animals. In contrast, none of these variables was significantly different from control values in animals banded for 24 wk. These observations indicate that depressed contractile state is not a fundamental characteristic of pressureinduced hypertrophied myocardium and reemphasize the important temporal relationship between contractile state and the imposition of sudden sustained loads.

\section{INTRODUCTION}

The changes in contractile state which accompany an increase in myocardial mass have been the subject of several investigations. Although earlier studies reported that contractile function of hypertrophied myocardium was normal or even "supernormal" $(1-4)$, the methods used to assess contractile state and the manner in which this function was corrected for differences in muscle mass have been criticized. More recently, Spann,

Received for publication 10 May 1974 and in revised form 16 August 1974.
Buccino, Sonnenblick, and Braunwald undertook a detailed assessment of contractile state of cat myocardium hypertrophied by pulmonary artery constriction, concluding that "nonfailing" hypertrophied myocardium was characterized by depressed contractile state (5). Subsequently, other investigators reported similar observations (6-9).

Although these conclusions have been widely accepted, it is possible that the results are a peculiarity of the method employed to increase afterload rather than a fundamental characteristic of pressure-induced hypertrophied myocardium. Meerson has reported that the development of myocardial hypertrophy produced by sudden sustained pressure loading is accompanied initially by marked depression of contractile state. However, in surviving animals, contractile function then improves (the stage of "stable hyperfunction"), before further deterioration and congestive heart failure ensue (10). In previous investigations, the vast majority of animals have been studied after relatively short periods of banding, usually less than 60 days. Thus, the depression of contractile state observed in these studies may have resulted from examination of muscles before sufficient time had elapsed for complete recovery of function. Also, it has been clearly demonstrated that contractile state of myocardium hypertrophied by volume loading is normal $(11,12)$, further suggesting that contractile state is more closely related to the conditions producing hypertrophy than to the increase in muscle mass per se.

The present study was undertaken to examine further the temporal relationship between sudden sustained pressure loading and the contractile state of the myocardium.

\section{METHODS}

Adult male and female cats (1.7-2.4 kg at entry), anesthetized with intraperitoneal pentobarbital $(30 \mathrm{mg} / \mathrm{kg}$ ) and artificially ventilated, underwent main pulmonary artery constriction with a circular band $4.0 \mathrm{~mm}$ in ID. The band was composed of polyethylene tubing, through which was 
inserted a copper wire of appropriate length and a silk suture. After the band was placed around the pulmonary artery, the ends of the copper wire were approximated and the silk suture was tied to prevent expansion. The circumference of the pulmonary artery at the site of constriction was measured before application of the band. 6 or $24 \mathrm{wk}$ later, surviving animals were again anesthetized and the chest reopened. Right atrial and ventricular pressures were obtained from a catheter inserted through the right atrial appendage. Cardiac output was determined in duplicate by the dye dilution method, with injection of indocyanine green dye into the right atrium and sampling from a short catheter inserted into the ascending aorta through a carotid artery. The heart was then removed and the right ventricular papillary muscles were dissected free and placed in a Lucite myograph containing a solution of the following millimolar composition: $\mathrm{Na}^{+} 144, \mathrm{~K}^{+} 4.0, \mathrm{Ca}^{++}$ 2.5, $\mathrm{Mg}^{++} 0.5, \mathrm{H}_{2} \mathrm{PO}_{4}^{-} 1.0, \mathrm{HCO}_{3}^{-} 25, \mathrm{Cl}^{-} 128$, and glucose 5.6. The solution was maintained at a temperature of $30^{\circ} \mathrm{C}$ and was bubbled vigorously with $95 \%$ oxygen-5\% $\mathrm{CO}_{2}$, which produced a $\mathrm{pH}$ of 7.4. The nontendinous end of the muscle was held rigidly by a plastic clip attached to a short metal rod, which passed through the bottom of the myograph and was connected to a Statham force transducer (Model Gl-4-250) (Statham Instruments, Inc., Oxnard, Calif.). To record muscle shortening, the tendinous end was secured by a short silk suture to the long arm (10:1 ratio) of a lever attached to a displacement transducer (Schaevitz Engineering, Camden, N. J.), Model R4BS), which in turn was secured to a rigid stand. A micrometer was held in place above each arm of the lever, permitting muscle length to be altered by known amounts or resting length to be held constant while load was varied. The compliance of the system without muscle was $2 \mu \mathrm{m} / \mathrm{g}$ and the equivalent mass of the lever was $150 \mathrm{mg}$. The muscle was stimulated by means of an American Electronic stimulator (American Electronic Laboratories, Inc., Colmar, Pa., Model $104 \mathrm{~A}$ ) at a frequency of $12 / \mathrm{min}$ and voltage $10 \%$ above threshold, with field electrodes parallel to the long axis of the muscle. The first derivatives of force development and muscle shortening were obtained by means of operational amplifiers. Force development, muscle shortening, their derivatives, and the stimulus artifact were recorded on a multichannel oscillograph.

Initially a small preload, generally $0.5 \mathrm{~g}$, was applied to the muscle, which was allowed to contact isotonically for 60-90 min. After appropriate placement of the micrometer stops, isometric length-tension curves were obtained by stretching the muscle by known increments from a point where active force development was just apparent to the first point at which active force declined from its maximum. In addition to developed force, the maximum rate of force development $(\mathrm{d} F / \mathrm{d} t)^{1}$ and the time to peak force were also determined at the peak of the isometric length-tension curve. The muscle was then again lightly preloaded and allowed to contract isotonically. After muscle shortening had returned to a value similar to that observed before the isometric study, resting muscle length was fixed at this light load and the force-velocity relationship determined by measuring maximal velocity of shortening after $0.5-\mathrm{g}$ increments in afterload. The muscle was then returned to the peak of the length-tension curve and allowed to contract isometrically. Active force at this time was es-

${ }^{1}$ Abbreviations used in this paper: $\mathrm{d} F / \mathrm{d} t$, maximum rate of force development; $L$ max, muscle length at peak active force development. sentially identical to that observed at the peak of the previously recorded isometric length-tension curve. Paired electrical stimulation was begun at a frequency of 12 pairs/ min with the interval between pairs adjusted to produce maximal force response. Small increments of norepinephrine were then added to the bath, which generally resulted in only a slight additional increase in active force. In preliminary studies, the addition of $\mathrm{Ca}^{++}$to the bath at this time did not result in further augmentation of active force. We have therefore termed developed force with paired stimulation and norepinephrine "maximal force".

Muscle length at peak active force development ( $L \max$ ) and the length at which the force-velocity curve was obtained were measured by means of a calibrated microscope. Cross-sectional area was determined from the weight of the papillary muscle and its length at $L$ max, assuming the muscle to be a cylinder with a specific gravity of 1.000 .

The atria and great vessels were removed from the remainder of the heart and the free wall of the right ventricle was dissected from the left ventricle and septum. Both wet and dry weights of the right ventricle and the left ventricle plus septum were measured; dry weight was obtained after exposure to $100^{\circ} \mathrm{C}$ for $24 \mathrm{~h}$.

All animals were kept in cages that measured 0.6 by 0.6 by $0.5 \mathrm{~m}$. Since activity was obviously restricted by cages of this size, two groups of control animals were studied. 17 animals were examined as described above after being placed in cages for 4-6 wk. Nine additional normal animals were studied after $24 \mathrm{wk}$ of observation to preclude changes due to prolonged inactivity.

Analysis of variance was utilized to determine the statistical significance of differences among groups (13).

\section{RESULTS}

Banding the pulmonary artery resulted in a reduction in cross-sectional area ranging from 55 to $85 \%$ (average $70 \%$ ). $30 \%$ of these animals died from congestive heart failure characterized by hepatomegaly, ascites, and bilateral pleural effusions. All deaths from heart failure occurred within 21 days of banding. 6 and 24 wk after banding, 19 and 11 animals, respectively, were sacrificed. However, data from only 11 of the former and 9 of the latter animals are included. This decision was based on the necessity of comparing muscles of comparable crosssectional area ; the detrimental effect of increasing crosssectional area on papillary muscle function has been well demonstrated previously (9). Since the cross sectional area of papillary muscles in the control animals did not exceed $2.0 \mathrm{~mm}^{2}$, only muscles $2.0 \mathrm{~mm}^{2}$ or less from the banded animals were utilized for analysis of data. If more than one muscle from an animal was less than $2.0 \mathrm{~mm}^{2}$, data from the smallest muscle were employed.

Comparison of ventricular weight, papillary muscle cross-sectional area, and hemodynamics among groups is presented in Table I.

Control animals studied after $24 \mathrm{wk}$ of observation had right ventricular-to-body weight ratios and left ventricular-to-body weight ratios significantly smaller than animals observed for $6 \mathrm{wk}(P<0.05)$. These differences 
TABLE I

Comparison of Anatomic and Hemodynamic Data among Groups

\begin{tabular}{|c|c|c|c|c|c|c|c|c|c|}
\hline & $\begin{array}{l}\text { Time after } \\
\text { entry }\end{array}$ & $n$ & $\begin{array}{l}\mathrm{RV} w \mathrm{wt} / \\
\text { body wt }\end{array}$ & $\begin{array}{l}\text { LV wt/ } \\
\text { body wt }\end{array}$ & $\begin{array}{l}R V w t / \\
L V w t\end{array}$ & $\begin{array}{l}\text { Papillary } \\
\text { muscle } \\
\text { cross-sectional } \\
\text { area }\end{array}$ & $\mathrm{CO}$ & $\begin{array}{c}\text { RV PR } \\
\text { S/D }\end{array}$ & RA PR \\
\hline & $w k$ & & $\mathrm{~g} / \mathrm{kg}$ & $g / k g$ & $g / g$ & $m m^{2}$ & $\mathrm{ml} / \mathrm{min} \mathrm{kg}^{-1}$ & $m m \mathrm{Hg}$ & $m m \mathrm{Hg}$ \\
\hline Controls & 6 & 17 & $\begin{array}{r}0.71 \\
\pm 0.04\end{array}$ & $\begin{array}{r}2.35 \\
\pm 0.10\end{array}$ & $\begin{array}{r}0.31 \\
\pm 0.01\end{array}$ & $\begin{array}{r}1.08 \\
\pm 0.06\end{array}$ & $\begin{array}{c}180 \\
\pm 21.2\end{array}$ & - & $\begin{array}{r}2.2 \\
\pm 0.6\end{array}$ \\
\hline Controls & 24 & 9 & $\begin{array}{r}0.58 \\
\pm 0.01\end{array}$ & $\begin{array}{r}1.86 \\
\pm 0.05\end{array}$ & $\begin{array}{r}0.31 \\
\pm 0.01\end{array}$ & $\begin{array}{r}1.09 \\
\pm 0.15\end{array}$ & $\begin{array}{c}133 \\
\pm 17.2\end{array}$ & $\begin{array}{c}23 / 2 \\
\pm 1.2 / 0.4\end{array}$ & $\begin{array}{r}2.8 \\
\pm 0.4\end{array}$ \\
\hline Banded & 6 & 11 & $\begin{array}{r}1.20 \\
\pm 0.06\end{array}$ & $\begin{array}{r}2.30 \\
\pm 0.06\end{array}$ & $\begin{array}{r}0.53 \\
\pm 0.02\end{array}$ & $\begin{array}{r}1.20 \\
\pm 0.06\end{array}$ & $\begin{array}{c}160 \\
\pm 21.2\end{array}$ & - & $\begin{array}{r}2.8 \\
\pm 0.6\end{array}$ \\
\hline Banded & 24 & 9 & $\begin{array}{r}0.98 \\
\pm 0.05\end{array}$ & $\begin{array}{r}1.96 \\
\pm 0.10\end{array}$ & $\begin{array}{r}0.50 \\
\pm 0.02\end{array}$ & $\begin{array}{r}1.40 \\
\pm 0.18\end{array}$ & $\begin{array}{c}127 \\
\pm 13.2\end{array}$ & $\begin{array}{c}57 / 2 \\
\pm 6.9 / 1.0\end{array}$ & $\begin{array}{r}3.1 \\
\pm 0.5\end{array}$ \\
\hline
\end{tabular}

Mean values $\pm S E M . R V$ wt, right ventricular weight; $L V$ wt, left ventricular weight; $C O$, cardiac output; $R V$ PR, right ventricular pressure; S/D, peak systolic/end-diastolic; RA PR, right atrial pressure.

appeared to be due to an increase in body fat during prolonged inactivity rather than any diminution in mass of the heart, since the liver-to-body weight ratio of the 24-wk control animals was also significantly less than that of the 6-wk controls. Right-to-left ventricular weight ratios in the control groups were identical. Banding resulted in an increase in right ventricular mass in all constricted animals, as evidenced by a right-to-left ventricular weight ratio in each banded animal that exceeded the largest ratio in the controls. The ratio of right ventricular weight to body weight in the 24-wkbanded animals was less than that observed in the 6-wkbanded group. However the increase in right ventricular mass in the banded animals was essentially identical when each group was compared to its respective control; the increase averaged $70 \%$ in both groups. The similarity of right-to-left ventricular weight ratios in banded groups is further evidence that the degree of right ventricular hypertrophy was comparable.

Dry weight was approximately $25 \%$ of wet weight and, as observed by others (5-7), there were no significant differences among groups.

There were no statistically significant differences in cardiac output or right atrial pressure among groups. None of the banded animals had a cardiac output less than $76 \mathrm{ml} / \mathrm{min} / \mathrm{kg}^{-1}$ or right atrial pressure exceeding $6 \mathrm{~mm} \mathrm{Hg}$, the lowest and highest values, respectively, in the control animals. Furthermore, there was no gross evidence of congestive heart failure in any of the banded animals at the time of sacrifice. Right ventricular pressures were measured only in the 24-wk-banded and control animals. The average right ventricular systolic pressure was approximately 2.5 times greater in the banded animals, whereas end-diastolic pressures were similar. The similarity of the increases in right ventricular mass in both banded groups suggests that the load was also comparable. Papillary muscle cross-sectional area among groups was not significantly different statistically.

Papillary muscle function data is presented in Figs. 1-4. Statistical analysis revealed no significant differences between the control groups in any of these variables, and the data were combined.

Although resting length-tension relationships among groups were essentially identical (Fig. 1), marked differences in active force development were observed. 6 wk after banding, active force at any given muscle length was significantly less than in the control and 24wk-banded groups. In contrast, active force development $24 \mathrm{wk}$ after banding was comparable to that of the control animals. Developed force at $\mathrm{L}$ max averaged $3.7 \pm 0.3(\mathrm{SEM})$ and $5.2 \pm 0.5 \mathrm{~g} / \mathrm{mm}^{2}$ in the 6- and 24wk-banded groups, respectively $(P<0.05)$, and $5.1 \pm 0.3$ $\mathrm{g} / \mathrm{mm}^{2}$ in the control cats (vs 6-wk, $P<0.01$ ).

Force-velocity relations were determined at an average preload of $0.40 \pm 0.03$ and $0.44 \pm 0.06 \mathrm{~g} / \mathrm{mm}^{2}$ in the 6 and 24-wk-banded groups, respectively, and $0.48 \pm 0.03 \mathrm{~g} / \mathrm{mm}^{2}$ in the control group: differences among groups are not statistically significant. $6 \mathrm{wk}$ after banding, the forcevelocity curve was shifted downward and to the left (Fig. 2). Velocity of muscle shortening at any given load was significantly less statistically than in the 24-wkbanded and control groups. Although muscle shortening velocity $24 \mathrm{wk}$ after banding was slightly less than the control value at all comparable loads, none of these differences is statistically significant. Maximal velocity of muscle shortening averaged $0.85 \pm 0.06$ and $1.05 \pm 0.07$ muscle lengths/s in the 6 and 24-wk-banded groups, re- 


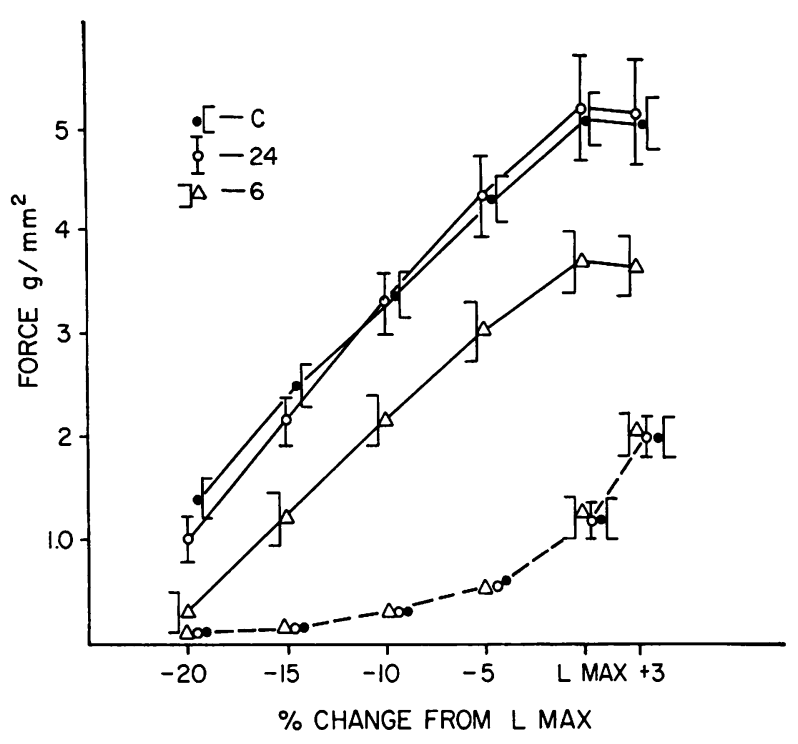

FIGURE 1 Compison of resting (--) and active (-) length-tension relations in control (C), 6-wk-banded, and 24-wk-banded animals. Values represent average of the group \pm SEM.

spectively, $(P<0.05)$ and $1.14 \pm 0.05$ muscle length $/ \mathrm{s}$ in the control group (vs. $6 \mathrm{wk}, P<0.01$ ).

6 wk after banding, $\mathrm{d} F / \mathrm{d} t$ (Fig. 3) was significantly less than that of the control and 24-wk-banded groups $(P<0.05$ for both), whereas the difference between the 24-wk-banded and control groups was not significant. Also the reduction in maximal force development (Fig. 4) 6 wk after banding was statistically significant when

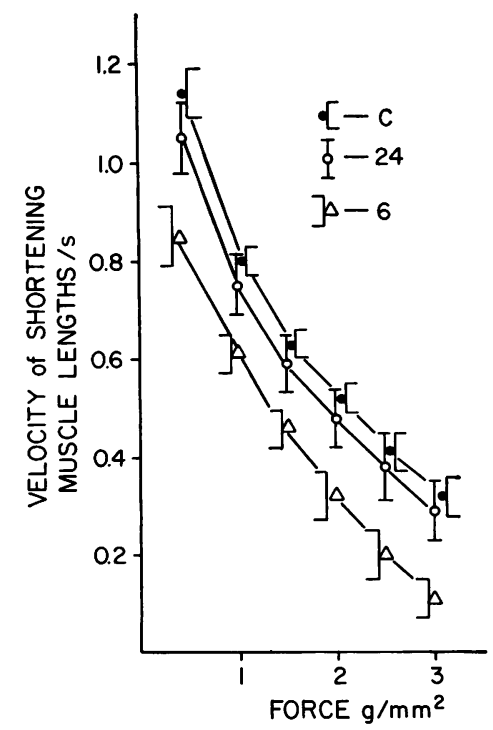

FIGURE 2 Comparison of force-velocity relations among groups. Symbols for groups are as in Fig. 1.

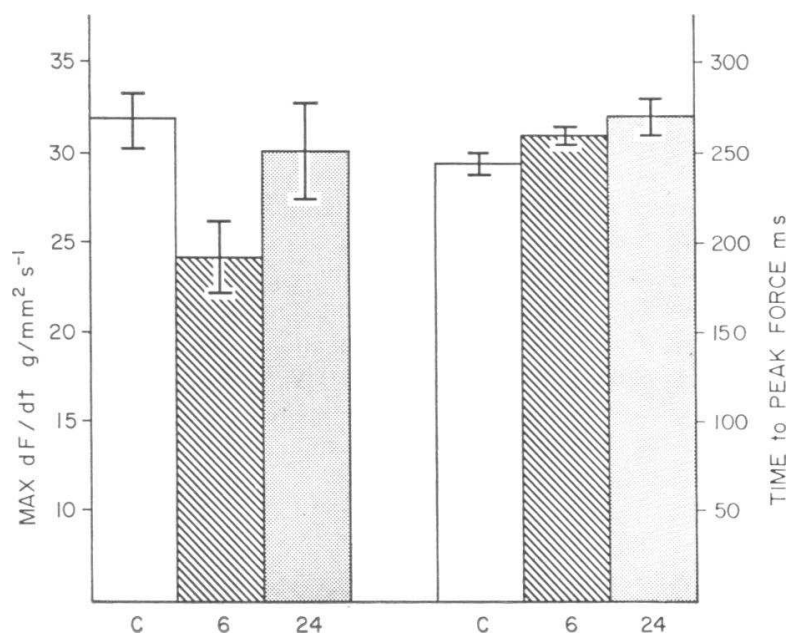

Figure 3 Left, comparison of $\mathrm{d} F / \mathrm{d} t$ at $L$ max. Right, comparison of times to peak isometric force at $L$ max. C, controls; 6, 6-wk-banded; 24, 24-wk-banded. Average values \pm SEM.

compared to both control and 24-wk-banded groups ( $P<$ 0.01 for both). The difference between the latter two groups was insignificant. The increments in force development with paired stimulation and norepinephrine were also comparable in the control and 24-wk-banded groups, averaging $59 \pm 6.0$ and $53 \pm 11.5 \%$, respectively.

Time to peak active force at $L \max$ (Fig. 3) was not significantly different among groups.

\section{DISCUSSION}

The major observation of this study, that contractile function of muscles studied 24 wk after banding was normal, indicates that depressed contractile state is not

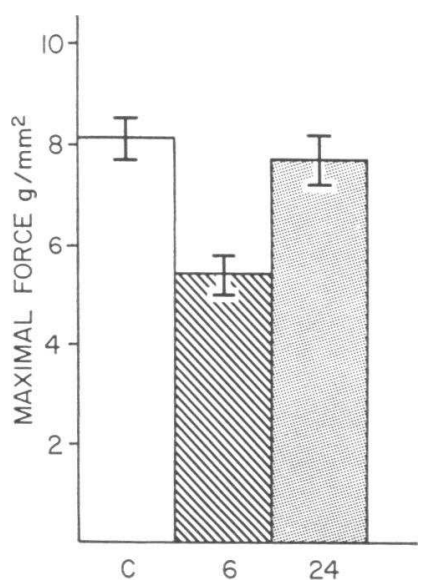

FIGURE 4 Comparison of isometric force development at $L$ max during paired electrical stimulation and addition of norepinephrine. C, controls; 6, 6-wk-banded; 24, 24-wkbanded. Average values \pm SEM. 
a fundamental characteristic of pressure-induced hypertrophied myocardium. Although this conclusion is opposed to that of many recent studies $(5-9,14)$, our results are not totally dissimilar. We did observe depressed contractile state of non-failing hypertrophied muscle when studies were performed $6 \mathrm{wk}$ after banding, and had we limited our studies to this time period, our conclusions, of course, would also be similar to those of the above investigations.

It was this striking difference in contractile function with comparable degrees of right ventricular hypertrophy in the 6 and 24-wk-banded groups that suggested that there was an important temporal relationship between contractile state and acute constriction. The occurrence of deaths from congestive heart failure helped to define this relationship further. In addition to contractile state, factors such as the rate and extent of increase in contractile mass must be important determinants of survival or death from heart failure after acute constriction. However, the high incidence of deaths from heart failure occurring exclusively within the first $3 \mathrm{wk}$ after banding indicates that a rapid and marked depression of contractile state accompanied acute constriction. Thereafter contractile state apparently improved gradually, with complete recovery occurring somewhere between 6 and $24 \mathrm{wk}$ after banding. This sequence of events is similar to that described by Meerson in aortic-constricted animals, i.e., an initial stage of myocardial "injury" followed by a stage of stable hyperfunction (10). Parenthetically, this latter stage appears to persist for a protracted period in our model, since we have now followed eight banded animals for more than a year and have not observed the late development of congestive heart failure in any.

In previous studies in which depressed contractile state has been observed, the majority of experiments were performed within 60 days of banding $(5,6,8,9)$. Furthermore, the data from muscles examined after different periods of constriction were generally grouped together. We believe the variation in time of study after banding and therefore the stage of myocardial response to pressure loading are primarily responsible for differing conclusions. A similar explanation probably accounts for the differences between the present study and that of Bassett and Gelband, who undertook a more systematic study of the effect of duration of constriction (7). Although they reported depressed contractile state at all periods after banding, the group studied after the most prolonged period of constriction apparently consisted of only six muscles from four animals and the duration of banding was for an unspecified period exceeding 90 days. On the other hand, Meerson and $\mathrm{Ka}$ pelko reported depressed contractile state in a significant number of animals both 2 and 6 mo after aortic con- striction (14). However, in their investigation, left ventricular pressure and its first derivative during aortic clamping were used as indices of contractile state, whereas corrections for differences in muscle mass were based on certain assumptions concerning ventricular geometry. As with earlier studies, the accuracy of these methods is questionable.

Our study differs from previous studies in several additional ways, most notably in the diameter of the constricting band and the frequency of stimulation employed in muscle studies, and these should be considered as possible causes for differing results. A single relatively slow frequency of stimulation was used in the present study to limit changes due to myocardial hypoxia. However, others have found no differences in force development or the rate of force development between hypertrophied and normal muscles as the frequency of contratcion was increased from 12 to $60 / \mathrm{min}$ (15). Similarly, Spann and co-workers found no difference in force development between nonfailing hypertrophied and normal muscles at frequencies between 6 and $48 / \mathrm{min}$, although the increment in maximum rate of rise of tension was somewhat less in hypertrophied muscles (5). We believe, therefore, that it is unlikely that a marked difference in contractile state between our control and 24-wk-banded animals would have become apparent at higher frequencies of stimulation. Furthermore, if slight differences were observed, it would be difficult to conclude that such differences represented alterations in contractile state. The papillary muscles of the banded animals were also slightly larger and therefore more subject to hypoxia and impaired function at higher frequencies of contraction (16).

Previous studies in the cat have employed bands of 2.8 and $3.5 \mathrm{~mm}$ ID (5-8). We utilized a clip of $4.0 \mathrm{~mm}$ ID because of excessive mortality with smaller clips in our hands. Although this would be expected to result in a lesser load and development of lesser degrees of hypertrophy, the increase in right ventricular mass in our study was comparable to that of previous studies. The increase in right ventricular mass approximated $90 \%$ of the study of Spann et al. (5) and $80 \%$ in that of Cooper, Satava, Harrison, and Coleman (8). In our study, the increase in right ventricular weight to left ventricular weight and right ventricular weight to body weight approximated $70 \%$ in both 6 and 24-wk-banded groups. It seems highly improbable that this modest difference in right ventricular mass accounts solely for our differing results. Furthermore, comparison by multiple regression analysis of right-to-left ventricular weight ratios, papillary muscle cross-sectional area, active force at $L \max$, and velocity of muscle shortening at the lightest load in the 24 -wk-banded animals revealed no significant relationship between the degree of hyper- 
trophy and force development or velocity of shortening. Although the extent of hypertrophy was deduced from the increase in mass of the right ventricular free wall, previous studies in this particular model have clearly demonstrated that the papillary muscle participates in the hypertrophic process $(5,6,8)$.

Other factors must also be considered in the interpretation of our data. The average cross-sectional area of the papillary muscles in this study was larger than optimum and some degree of hypoxia may well have been present (16-18). Although the use of smaller papillary muscles would have been desirable, it is extremely difficult to obtain a large number of such muscles in banded cats. Had we limited this study to hypertrophied muscles less than $1.0 \mathrm{~mm}^{2}$, only two of the 6 -wk-banded and three of the 24-wk-banded animals would have been utilized. We therefore elected to use larger muscles but ones of comparable cross-sectional area. This was done by employing only those hypertrophied muscles whose crosssectional area was within the range of the control muscles, and statistically no significant differences in cross-sectional area among groups existed.

To assess contractile state, contractile element function and active state should be measured. To express our data of muscle function in terms of contractile element function would require knowledge of the most appropriate model for cardiac muscle, a subject that has recently been reviewed (19-20). Since the most appropriate model has not been determined, and, since we did not make detailed measurements of active state, it is not possible to conclude conclusively that our measurements reflect changes in contractile state. Nevertheless, $24 \mathrm{wk}$ after banding, none of the measured functions of the muscle were significantly different statistically from the control animals. Furthermore, the comparable times to peak isometric force among groups suggest that duration of active state was also similar (21). The evidence strongly suggests that our conclusion regarding contractile state derived from measurements of muscle function is valid.

Certain characteristics of the hypertrophied muscles would tend to magnify rather than mask potential differences from the controls in contractile function, further supporting our interpretations. As stated above, papillary muscle cross-sectional area was also slightly larger in the banded animals, a factor which would tend to reduce force development. Alterations in the nonmuscular components of hypertrophied myocardium also may have affected both force and velocity development. Previous studies have demonstrated conclusively that collagen concentration is increased in hypertrophied myocardium $(6,9,22)$. This would imply a decrease in contractile components per unit of cross-sectional area. Therefore, the force generated by each contractile ele- ment of hypertrophied muscle may actually be larger than that calculated as force per square millimeter. Since force and velocity are inversely related, this would result in a lower velocity of shortening than that of control animals at comparable calculated loads. We do not mean to imply that myocardial contractile state of 24wk-banded animals was supernormal. However, these factors may account for the slight, albeit not significant, differences in muscle function between the 24-wk-banded and control groups. Neither factor accounts for the differences in contractile function between our banded groups, since the increase in right ventricular mass was comparable and papillary muscle cross-sectional area was even greater in the 24-wk-banded animals.

Two relatively recent studies have also reported normal contractile state in pressure-induced hypertrophied myocardium. Fisher and Kavaler studied papillary muscle mechanics in situ in dogs in which the pulmonary artery had been banded for 6-16 wk (23). They reported normal maximal force development and $\mathrm{dF} / \mathrm{dt}$ in this model. Of considerable interest is the study of Pannier, who reported normal force development and velocity of shortening of hypertrophied papillary muscles in pulmonary artery-banded cats studied 2 and 6 mo after banding (15). However, in both studies the increase in right ventricular mass was less than in the studies reporting depressed contractile state, leading the authors to conclude that this may have been responsible for the differing results. The present study demonstrates the importance of other factors, as well as emphasizing that depressed contractile state is not a fundamental characteristic of pressure-induced hypertrophy.

There is increasing interest in the use of this model to elucidate the functional and structural changes producing or associated with myocardial failure. Our results indicate that caution must be exercised in interpreting data derived from such models. Although marked depression of contractile state and a high incidence of congestive heart failure occur within the first few weeks after banding, the changes during this period may represent the myocardial response to abrupt pressure loading. This response may differ from that which occurs when the load is applied much less acutely, as is commonly encountered in the clinical situation. Furthermore, the gradual normalization of contractile state which follows this early period of depression suggests that measurements made during this period may reflect processes associated with the restoration of normal myocardial function rather than characteristics of failing or non-failing hypertrophied myocardium.

We would emphasize that the exact temporal relationship between contractile state and banding observed in this study may not apply to other animal models or different degrees of constriction. 


\section{ACKNOWLEDGMENTS}

We are deeply grateful to Mrs. Jeanne Arceneaux for her secretarial assistance in the preparation of this manuscript.

This study was supported by U. S. Public Health Service Grants HL 13639 and HL 05940.

\section{REFERENCES}

1. Beznak, M. 1958. Cardiac output in rats during the development of cardiac hypertrophy. Circ. Res. 6: 207212.

2. Kerr, A., Jr., A. R. Winterberger, and M. Giambattista. 1960. Tension developed by papillary muscles from hypertrophied rat hearts. Circ. Res. 9: 103-105.

3. Grimm, A. F., R. Kubota, and W. V. Whitehorn. 1963. Properties of myocardium in cardiomegaly. Circ. Res. 12: 118-124.

4. Geha, A. S., J. P. Duffy, and H. J. C. Swan. 1966. Relation of increase in muscle mass to performance of hypertrophied right ventricle in the dog. Circ. Res. 19: 255-259.

5. Spann, J. F., Jr., R. A. Buccino, E. H. Sonnenblick, and E. Braunwald. 1967. Contractile state of cardiac muscle obtained from cats with experimentally produced ventricular hypertrophy and heart failure. Circ. Res. 21 : 341-354.

6. Kaufmann, R. L., H. Homburger, and H. Wirth. 1971. Disorder in excitation-contraction coupling of cardiac muscle from cats with experimentally produced right ventricular hypertrophy. Circ. Res. 28: 346-357.

7. Bassett, A. L., and H. Gelband. 1973. Chronic partial occlusion of the pulmonary artery in cats: change in ventricular action potential configuration during early hypertrophy. Circ. Res. 32: 15-26.

8. Cooper, G., IV., R. M. Satava, Jr., C. E. Harrison, and H. N. Coleman, III. 1973. Mechanism for the abnormal energetics of pressure-induced hypertrophy of cat myocardium. Circ. Res. 33: 213-223.

9. Bing, O. H. L., S. Matsushita, B. L. Fanburg, and H. J. Levine. 1971. Mechanical properties of rat cardiac muscle during experimental hypertrophy. Circ. Res. 28: 234-245.

10. Meerson, F. Z. 1969 . Myocardium in hyperfunction, hypertrophy and heart failure. Circ. Res. 25 (Suppl. 2) : 1-163.
11. Ross, J., Jr., and W. H. McCullagh. 1972. Nature of enhanced performance of the dilated left ventricle in the dog during chronic volume overloading. Circ. Res. 30 : $549-556$.

12. Cooper, G., F. J. Puga, K. J. Zujko, C. E. Harrison, and H. N. Coleman. 1973. Normal myocardial function and energetics in volume overload hypertrophy in the cat. Circ. Res. 32 : 140-148.

13. Snedecor, G. W. 1956. Statistical Methods. Iowa State University Press, Ames, Iowa. 5th edition. 237 pp.

14. Meerson, F. Z., and V. I. Kapelko. 1972. The contractile function of the myocardium in two types of cardiac adaptation to a chronic load. Cardiology. 57 : 183-199.

15. Pannier, J. L. 1971. Contractile state of papillary muscles obtained from cats with moderate right ventricular hypertrophy. Arch. Int. Physiol. Biochim. 79: 743-752.

16. Koch-Weser, J. 1963. Effect of rate changes on strength and time course of contraction of papillary muscle. Am. J. Physiol. 204 : 451-457.

17. Cranefield, P. F., and K. Greenspan. 1960. The rate of oxygen uptake of quiescent cardiac muscle. J. Gen. Physiol. 44: 235-249.

18. Coleman, H. N., III. 1967. Role of acetylstrophanthidin in augmenting myocardial oxygen consumption. Circ. Res. 21 : 487-495.

19. Pollack, G. H., L. L. Huntsman, and P. Verdugo. 1972. Cardiac muscle models. An overextension of series elasticity. Circ. Res. 31 : 569-579.

20. Noble, M. I. M., and W. Else. 1972. Re-examination of the applicability of the Hill model to cat myocardium. Circ. Res. 31: 580-589.

21. Sonnenblick, E. H. 1967. Active state in heart muscle, its delayed onset and modification by inotropic agents. J. Gen. Physiol. 50: 661-676.

22. Buccino, R. A., E. Harris, J. F. Spann, Jr., and E. H. Sonnenblick. 1969. Response of myocardial connective tissue to development of experimental hypertrophy. Am. J. Physiol. 216: 425-428.

23. Fisher, V. J., and F. Kavaler. 1971. Maximal force development of hypertrophied right ventricular papillary muscles remaining in situ. In Cardiac Hypertrophy. N. R. Alpert, editor. Academic Press, Inc., New York. 371-386. 